\title{
Assessment of antimicrobial prescribing and rationality of drug usage in general practitioners in Pune city, India
}

\author{
Kushal D. Sarda*, Vijaya A. Pandit
}

Department of Pharmacology, Bharati Vidyapeeth Deemed University Medical College, Dhankawadi, Pune-411043, Maharashtra, India

Received: 4 December 2013 Accepted: 15 December 2013

*Correspondence to:

Dr. Kushal D. Sarda,

Email: kdsarda@gmail.com

(C) 2014 Sarda KD et al. This is an open-access article distributed under the terms of the Creative Commons Attribution Non-Commercial License, which permits unrestricted non-commercial use, distribution, and reproduction in any medium, provided the original work is properly cited.

\begin{abstract}
Background: Most of the common ailments are managed by general practitioners (GPs). GPs prescribe major bulk of the drugs sold in the market. Naturally, irrational use of drugs at this level could lead to disastrous consequences. So this study was undertaken to determine prescribing pattern of Antimicrobials (AMA) and the rationality of drug usage by GPs in Pune city.

Methods: It was a cross-sectional study. Pune city was divided into 5 zones. MBBS, BAMS and BHMS GPs doing Allopathic practice were selected randomly. 2 GPs of each specialty per zone were selected; this gave us 10 GPs of each degree - so total 30 GPs.30 Prescriptions at each GP were collected total 900 prescriptions. The following parameters were studied- Diagnosis of patient, Average no. of drugs/prescription Percentage of AMAs prescribed, Rationality of AMA, Selection of AMAs diagnosis wise, Rationality of Prescription.

Results: More than $75 \%$ patients coming to GPs were suffering from communicable diseases. Average no. of drugs / prescription and percentage of prescription with AMAs was high in all GPs. Macrolides was the most common group of AMA used by MBBS whereas Cephalosporins was used by BAMS and BHMS. Irrational use of AMAs was high in BHMS GPs. Use of irrational FDCs, banned drugs, steroids was high in BAMS GPs.

Conclusions: There are deficiencies in prescription practices among all GPs. Not only are GPs prescribing the highest number of AMAs per prescription anywhere, their prescription practices for common health problems are highly inappropriate. High level of irrational use of drugs by BAMS and BHMS GPs are cause of concern.
\end{abstract}

Keywords: Antibiotic, Medical practitioners, Rationality, Communicable diseases, FDCs

\section{INTRODUCTION}

WHO defines rational use of drug as "Patients should receive medication appropriate to their clinical needs, in doses that meet their own individual requirements for an adequate period of time, and the lowest cost to them and their community". ${ }^{1}$ It has been estimated that fifty percent of medicines being used in India, either on prescription or in over-the-counter sales, are inappropriately or irrationally used. ${ }^{2}$ Recently there has been an alarming concern over the injudicious use of many drugs worldwide. Amongst them, important ones are -AMAs (Antimicrobials), Corticosteroids, Analgesics, Antacids, Acid reducing agents, Vitamins and use of many irrational drug combinations. ${ }^{3}$ The practice of indiscriminate prescribing of AMAs is posing a major problem of ineffective and unsafe treatment, exacerbation or prolongation of illness, distress and harm to the patient as well as an additional burden of an expensive medical cost for the patient and importantly development of drug resistance. $^{4}$

Irrational prescription of drugs is of common occurrence in clinical practice, important reasons being lack of knowledge about drugs, unethical drug promotions and irrational prescribing habits of clinicians. ${ }^{5}$ Monitoring of prescriptions and drug utilization studies can identify the 
problems and provide feedback to prescribers so as to create awareness about irrational use of drugs. ${ }^{6}$

General Practitioner is the most sought out healthcare provider as has been confirmed by number of studies. ${ }^{7}$ Most of the common ailments are managed by medical practitioners or general practitioners (GPs). GPs prescribe major bulk of the drugs sold in the market. Naturally, irrational use of drugs at this level could lead to disastrous consequences. ${ }^{8}$

Patients with fever, loose motions, and upper respiratory infections generally are treated by General Practitioners, who are also called as Family Doctors. GP is a practitioner who treats acute and chronic illnesses and provides preventive care and health education. GPs in Pune city are mainly of MBBS, BAMS, BHMS qualifications though people with other qualifications (BUMS, LCEH) also are found in small numbers.

So present study was planned to study the prescribing pattern and rationality of drug use by general practitioners in Pune city.

\section{METHODS}

After the approval of Institutional Ethics Committee this cross sectional comparative study was conducted for the period of 3 months (From July 2012 to September 2012) in Pune city. MBBS, BAMS and BHMS GPs doing Allopathic practice in Pune city who were listed with Indian Medical Association, Pune Branch were selected. Pune city was divided into five zones - North, South, East, West and Central zone. GPs were divided zone wise. Two practitioners of each specialty per zone were selected randomly using online software (www.randomiser.org). This gave us ten practitioners of each degree spread over Pune city - so total 30 practitioners. Selected GPs were approached and informed consent was obtained. Detailed indicators encounter form developed by WHO was used for data collection. We included all patients of any age and either sex getting treated on OPD basis. Data was collected of 30 patients per prescriber. So, data of 900 prescriptions was collected.

Patient's demographic data - age, sex and diagnosis was considered and also chief complaints for which medical advice was sought. Drug history i.e. dose, dosage, amount of drug used or use of other corrective measures and any other remarks were also seen. The collected prescriptions were evaluated for

1. Rationality of antibiotics

2. Rationality of prescriptions

3. Overall prescription: appropriate or inappropriate

1. Rationality of antibiotics

a) Percentage of encounters with an antibiotic prescribed. b) Use of Antimicrobial agents.

c) Selection of Antibiotics diagnosis wise.

d) ABC Category $^{9}$

A - Rational - AMA used with its route of administration, dose, frequency and duration of use were appropriate for infection. Rationality was evaluated according to Current Medical Diagnosis \& Treatment (CMDT), McGraw Hill LANGE 2012. ${ }^{10}$

B - Irrational - AMA used without indication, prophylaxis under circumstances of unproven efficacy or by clearly inappropriate route, dose or preparation for that indication.

C - Questionable - when insufficient clinical or laboratory data was present to enable the therapy to be classified as clearly rational or irrational.

2. Rationality of prescriptions

a) Number of drugs prescribed.

b) Average number of drugs per prescription.

c) Use of Fixed Dose Combinations (FDCs)

d) Use of Banned Drugs.

e) Use of Steroids.

f) Use of Oral Rehydration Solution (ORS) in Acute Gastroenteritis (AGE) patients.

g) Overprescribing - drug prescribed unnecessarily either overdose or longer period

h) Underprescribing - drug prescribed for shorter duration and is not effective, an aggressive or an expensive treatment may be needed later. ${ }^{11}$

3. Overall prescription: appropriate or inappropriate

The prescription containing one of the irrational AMAs, irrational FDCs, banned drugs, steroids, no ORS, overprescribing, underprescribing were considered as inappropriate.

FDCs and Banned drugs were assessed by considering CDSCO List. Averages, Percentages were calculated using - Microsoft Excel. For comparison between groups following test were used- Chi-square $(\chi 2)$ test for percentages and Kruskal-Wallis test for averages. Tests were performed using GraphPad Prism version 6.00 for Windows, GraphPad Software, La Jolla California USA, www.graphpad.com.

\section{RESULTS}

Figure 1 and Figure 2 show that Age and Sex wise distribution of patients with MBBS, BAMS and BHMS practitioners were comparable.

Distribution of patients based on diagnosis (Figure 3) was also similar across MBBS, BAMS and BHMS GPs. More than $75 \%$ patients coming to GPs were suffering from communicable diseases. In communicable diseases, 
Respiratory infections and Acute Gastroenteritis were most common infections encountered in general practice. Viral fever and Urinary Tract Infections (UTI) composed of $12 \%$ and $6 \%$ respectively.

In non-communicable diseases, Gastritis was common followed by Hypertension, Anemia and Diabetes mellitus. It was seen that patients with Hypertension and Diabetes mellitus prefer MBBS GPs more than BAMS and BHMS GPs. Others included Skin \& Soft tissue infections (SSTI), Abscess, low backache and bodyache.

For further analysis of prescriptions we considered the most common diseases encountered in study that were Upper Respiratory Tract Infections (URTI), Lower Respiratory Tract Infections (LRTI), Viral fever, Acute Gastroenteritis (AGE) and Urinary Tract Infections (UTI).

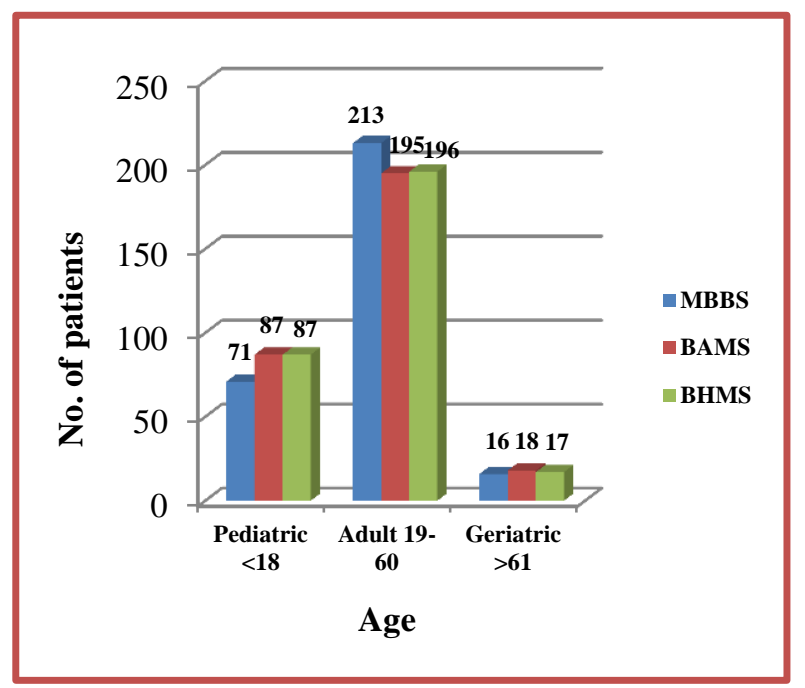

Figure 1: Distribution of patients based on age.

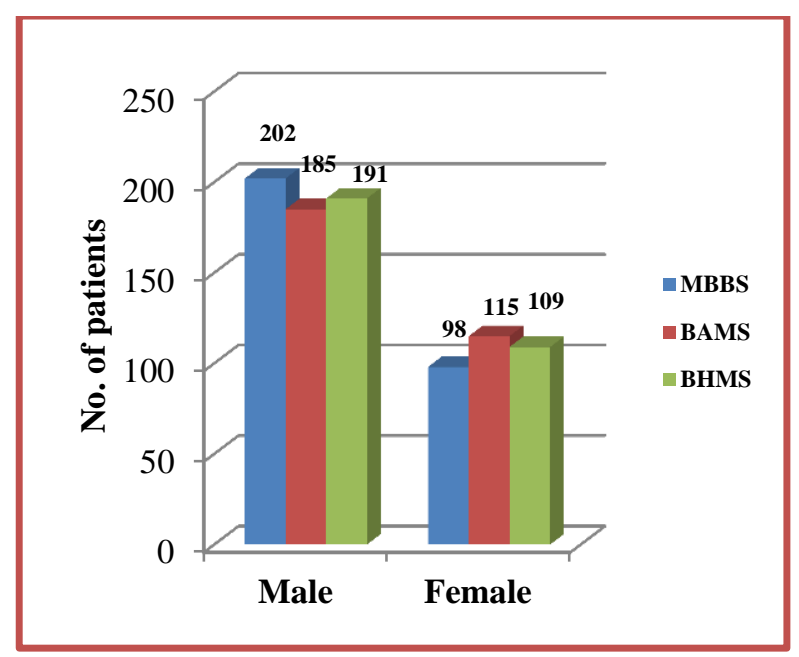

Figure 2: Distribution of patients based on sex.

Table 1 shows percentage of the prescriptions contained antimicrobial agents (AMAs). In MBBS and BAMS GPs, one GP had more than $90 \%$ of the prescriptions containing AMAs. In case of two BHMS GPs, more than $90 \%$ of the prescriptions contained AMAs.

Table 2 shows use of various groups of AMAs. $\beta$-lactam, fluoroquinolones (FQ) and macrolides were important group of AMAs used in the treatment of infections. From table it was evident that cephalosporins were significantly more frequently used by BAMS and BHMS GPs $(\mathrm{P}<0.05)$. Other AMAs include tetracyclines, antivirals, antimalarial, antifungal, etc.

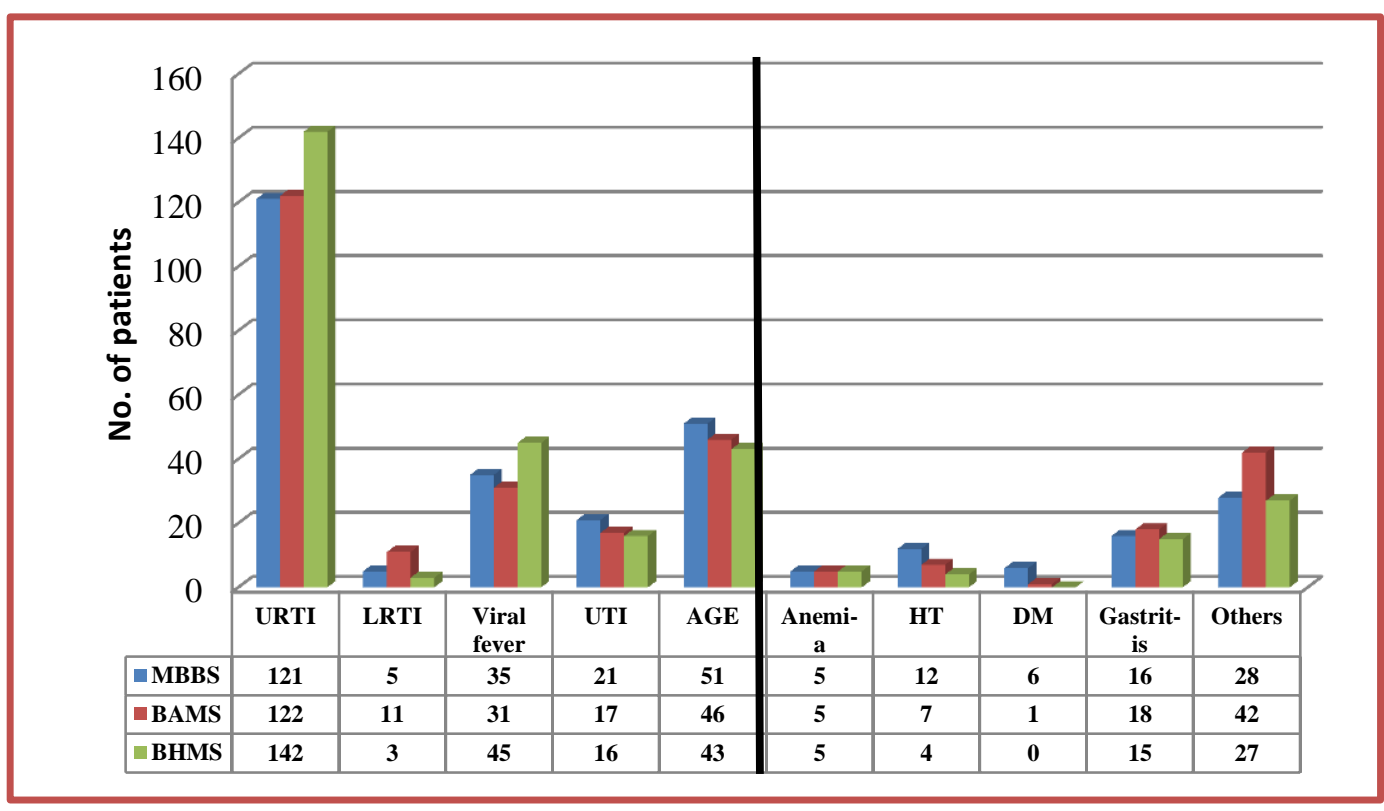

Figure 3: Distribution of patients based on diagnosis. 
Table 1: Percentage of encounters with an antibiotic prescribed.

\begin{tabular}{|l|l|l|l|l|}
\hline AMAs & MBBS & BAMS & BHMS & p-value \\
\hline $\begin{array}{l}\text { Percentage } \\
\text { of } \\
\text { prescription }\end{array}$ & $78.33 \%$ & $77.33 \%$ & $76.66 \%$ & $\mathrm{p}=0.99$ \\
$\begin{array}{l}\text { with } \\
\text { antibiotics }\end{array}$ & & & & \\
\hline
\end{tabular}

Table 2: Use of antimicrobials agents (AMAs).

\begin{tabular}{|lllll|}
\hline AMAs & $\begin{array}{l}\text { MBBS } \\
(\mathbf{n}=\mathbf{2 5 0})\end{array}$ & $\begin{array}{l}\text { BAMS } \\
(\mathbf{n}=\mathbf{2 3 7})\end{array}$ & $\begin{array}{l}\text { BHMS } \\
(\mathbf{n}=\mathbf{2 3 2})\end{array}$ & $\mathbf{p}$-value \\
\hline Fluoroquinolones & $\begin{array}{l}48 \\
(19.2)\end{array}$ & $\begin{array}{l}33 \\
(13.93)\end{array}$ & $\begin{array}{l}38 \\
(16.37)\end{array}$ & $\mathrm{p}=0.59$ \\
\hline Penicillins & $\begin{array}{l}43 \\
(17.2)\end{array}$ & $\begin{array}{l}36 \\
(15.19)\end{array}$ & $\begin{array}{l}37 \\
(16.37)\end{array}$ & $\mathrm{p}=0.92$ \\
\hline Cephalosporins & $\begin{array}{l}38 \\
(15.20)\end{array}$ & $\begin{array}{l}68 \\
(28.69)\end{array}$ & $\begin{array}{l}72 \\
(31.03)\end{array}$ & $\mathrm{p}=0.02 *$ \\
\hline Macrolides & $\begin{array}{l}59 \\
(23.60)\end{array}$ & $\begin{array}{l}55 \\
(23.20)\end{array}$ & $\begin{array}{l}41 \\
(17.67)\end{array}$ & $\mathrm{p}=0.53$ \\
\hline \multirow{2}{*}{ Others } & $\begin{array}{l}62 \\
(24.80)\end{array}$ & $\begin{array}{l}45 \\
(18.98)\end{array}$ & $\begin{array}{l}44 \\
(18.96)\end{array}$ & $\mathrm{p}=0.49$ \\
\hline
\end{tabular}

As could be seen from Figure 4, $\beta$-lactam and macrolides were commonly used for URTI. Whereas combination of fluoroquinolones with imidazole was mostly used in AGE. $6.61 \%$ and $37.15 \%$ patients of URTI and Viral fever respectively were treated without AMAs by MBBS GPs.

BAMS GPs (Figure 5) treating URTI, cephalosporins were used more commonly $(38.53 \%)$ followed by macrolides (36.89\%) and penicillins (17.21\%). 1.64\% and $12.90 \%$ patients of URTI and Viral fever respectively were treated without AMAs. $4.36 \%$ patients of were treated without AMA.

As could be seen in Figure 6, 15.49\% and 13.35\% patients of URTI and Viral fever respectively were treated without AMAs. In BHMS GPs, patients with URTI treated without AMAs was statistically significant as compared with MBBS and BAMS GPs $(\mathrm{P}=0.01, \chi 2=$ 8.5 , df-2).

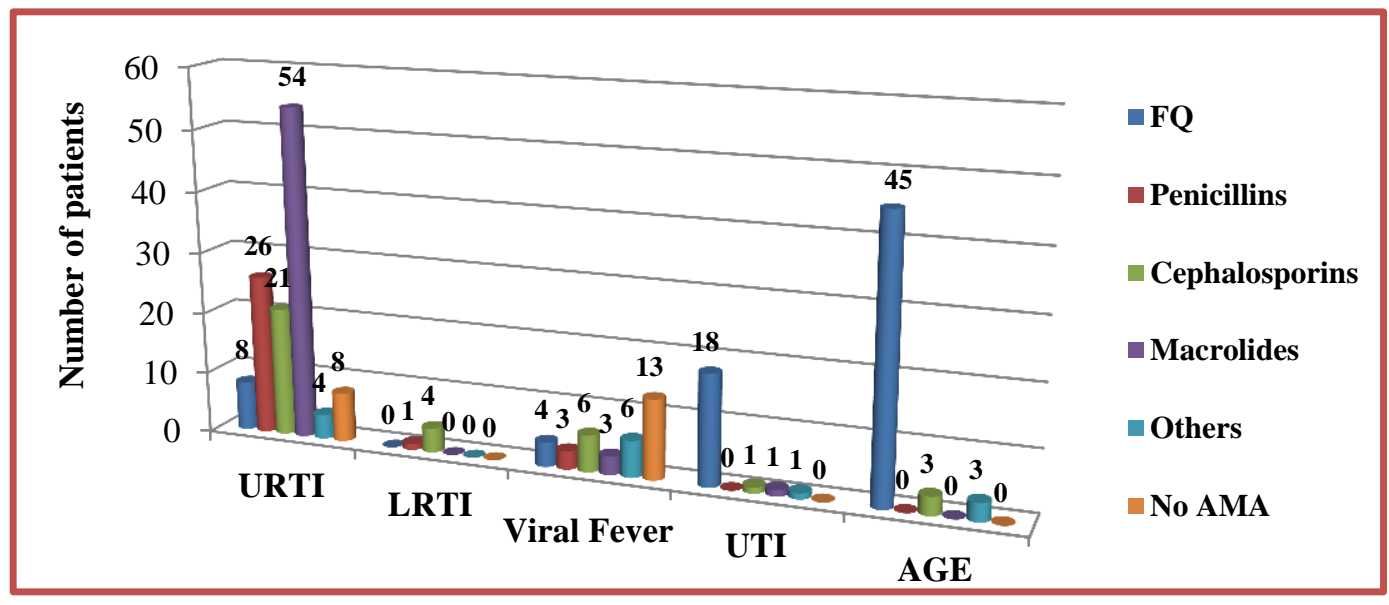

Figure 4: Selection of AMAs (Diagnosis wise) by MBBS GPs.

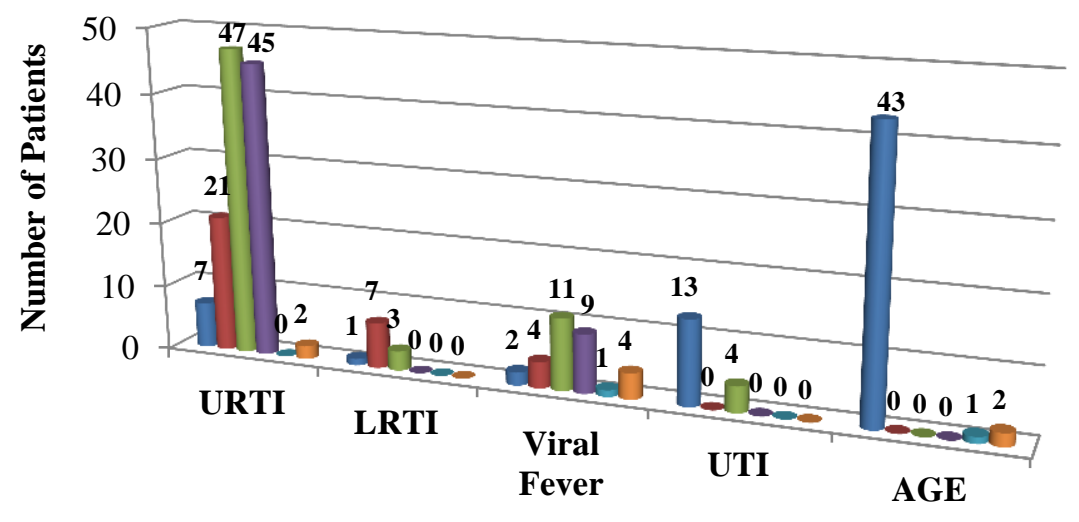

FQ

- Penicillins

- Cephalosporins

- Macrolides

Others

- No AMA

Figure 5: Selection of AMAs (Diagnosis wise) by BAMS GPs. 


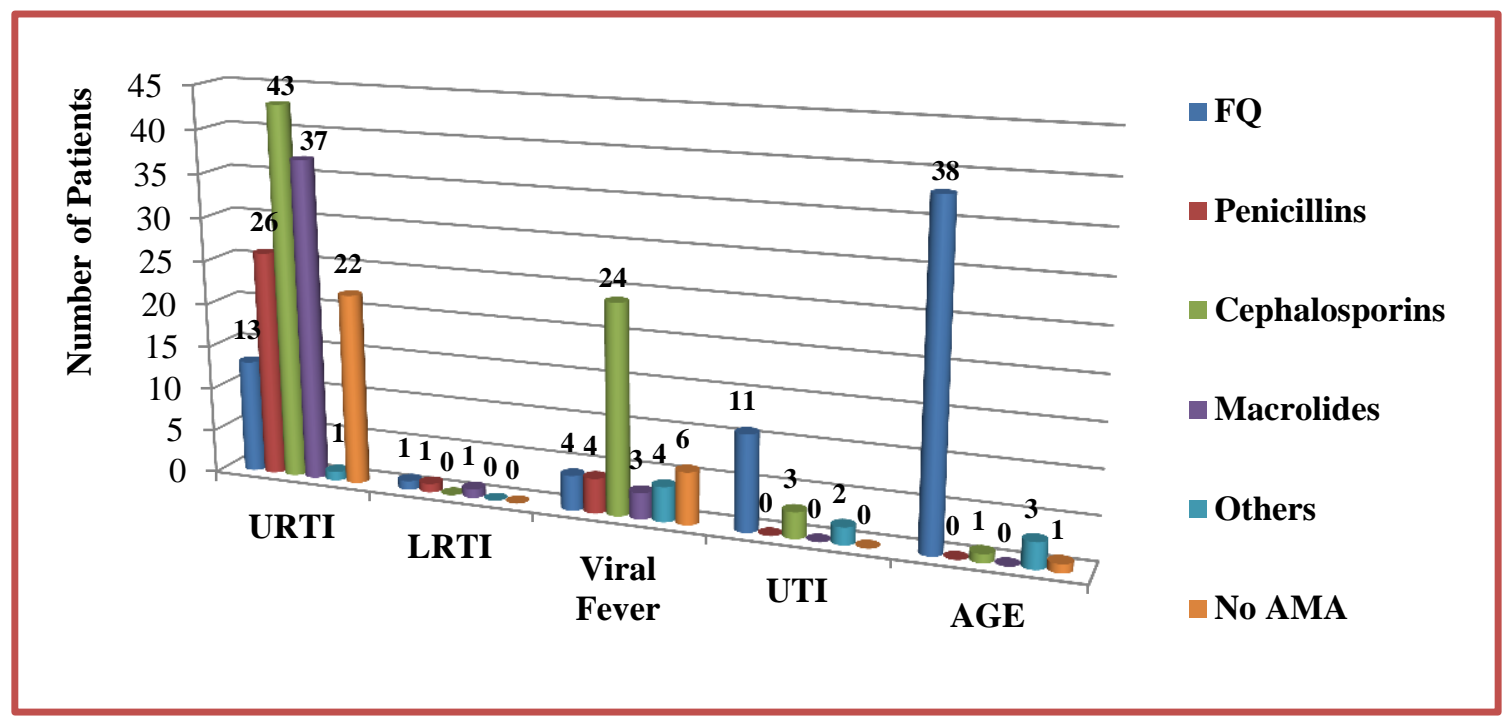

Figure 6: Selection of AMAs (Diagnosis wise) by BHMS GPs.

Table 3: Evaluation of rationality of antimicrobial therapy (ABC Criteria).

\begin{tabular}{|c|c|c|c|c|}
\hline $\begin{array}{l}\text { Evaluation } \\
\text { (Category) }\end{array}$ & $\begin{array}{l}\text { MBBS } \\
(n=236)\end{array}$ & $\begin{array}{l}\text { BAMS } \\
(n=232)\end{array}$ & $\begin{array}{l}\text { BHMS } \\
(\mathbf{n}=\mathbf{2 3 0})\end{array}$ & p value \\
\hline Rational (A) & $\begin{array}{l}187 \\
(79.23)\end{array}$ & $\begin{array}{l}124 \\
(53.44)\end{array}$ & $\begin{array}{l}118 \\
(51.30)\end{array}$ & $\mathrm{p}=0.008 * *$ \\
\hline $\begin{array}{l}\text { Irrational } \\
\text { (B) }\end{array}$ & $\begin{array}{l}36 \\
(15.25)\end{array}$ & $\begin{array}{l}78 \\
(33.62)\end{array}$ & $\begin{array}{l}95 \\
(41.30)\end{array}$ & $\mathrm{p}=0.0005^{* * *}$ \\
\hline $\begin{array}{l}\text { Questionable } \\
\text { (C) }\end{array}$ & $\begin{array}{l}13 \\
(5.50)\end{array}$ & $\begin{array}{l}30 \\
(12.93)\end{array}$ & $\begin{array}{l}17 \\
(7.40)\end{array}$ & $\mathrm{p}=0.15$ \\
\hline
\end{tabular}

$* * \mathrm{p}<0.01 * * * \mathrm{p}<0.001 \quad$ Values in parentheses are in percentages $(\%)$

As evident from above Table 3, evaluation of AMA therapy is categorized in three:
Rational (A): MBBS GPs prescribed AMAs more rationally $(79.23 \%)$ in comparison to BAMS $(53.44 \%)$ and BHMS $(51.30 \%)$ GPs which was statistically significant $(\mathrm{P}=0.008)$. More than half the prescriptions of BAMS and BHMS GPs were not rational.

Irrational (B): BHMS GPs prescribed 41.30\% irrational AMAs as compared to BAMS (33.62\%) and MBBS $(15.25 \%)$ GPs which was statistically significant $(\mathrm{P}=0.0005)$.

Questionable (C): $12.93 \%$ of BAMS GPs prescribed AMAs having questionable role in comparison to BHMS $(7.40 \%)$ and MBBS $(5.50 \%)$. But the variation was not statistically significant.

Table 4: Rationality of prescriptions.

\begin{tabular}{|l|llll|}
\hline & $\begin{array}{l}\text { MBBS } \\
(\mathbf{n = 3 0 0})\end{array}$ & $\begin{array}{l}\text { BAMS } \\
(\mathbf{n = 3 0 0})\end{array}$ & $\begin{array}{l}\text { BHMS } \\
(\mathbf{n}=300)\end{array}$ & p value \\
\hline Total number of drugs prescribed & 1188 & 1497 & 1389 & \\
\hline $\begin{array}{l}\text { Average no. of drugs Per Prescription } \\
\text { (95\% confidence Interval) }\end{array}$ & $\begin{array}{l}3.95( \pm 0.92)^{*} \\
(3.38-4.52)\end{array}$ & $\begin{array}{l}4.98( \pm 0.78)^{*} \\
(4.49-5.47)\end{array}$ & $\begin{array}{l}4.64( \pm 0.83) \\
(4.12-5.16)\end{array}$ & $\mathrm{p}=0.053$ \\
\hline Fixed Dose Combinations & $296(24.92)$ & $286(19.10)$ & $257(18.50)$ & $\mathrm{p}=0.027^{*}$ \\
\hline Steroids & $17(5.66)$ & $67(22.33)$ & $57(19.00)$ & $\mathrm{p}<0.0001^{* * * *}$ \\
\hline Banned Drugs & $3(1.00)$ & $19(6.33)$ & $4(1.33)$ & $\mathrm{p}=0.014^{*}$ \\
\hline No ORS in AGE & $2(3.92)$ & $17(36.95))$ & $11(25.58)$ & $\mathrm{p}=0.016^{*}$ \\
\hline Overprescribing & $27(9.00)$ & $50(16.66)$ & $62(20.66)$ & $\mathrm{p}=0.023^{*}$ \\
\hline Underprescribing & $33(11.00)$ & $69(23.00)$ & $24(8.00)$ & $\mathrm{p}=0.002^{* *}$ \\
\hline
\end{tabular}

${ }^{1}$ Data is expressed as mean \pm one standard deviation. Kruskal-Wallis test followed by post hoc Dunn's multiple comparisons test. MBBS vs BAMS is significant. $* \mathrm{p}<0.05 * * \mathrm{p}<0.01 \quad * * * * \mathrm{p}<0.0001$. Values in parentheses are in percentages $(\%)$ except for average number of drugs per prescription.

Total number of drugs prescribed was high in BAMS GPs (Table 4). Average No. of drugs prescribed was 3.95 per prescription for MBBS GPs. In case of four of the
GPs, this average was above 4.5.In BAMS GPs it was 4.98 per prescription. In case of one of the BAMS GPs, this average was above 6. In BHMS GPs it was 4.64 per 
prescription. In case of one of the BHMS GP, this average was above 6 and in case of two GPs this average was more than 5 .

Fixed dose combination: amoxicillin + clavulanic acid and FQ + imidazoles were AMA combinations used by all GPs. Cough syrup, anticold combination and multivitamin preparations were also used by all.

Steroids: dexamethasone was most common steroid dispensed by BAMS (22.33\%) and BHMS (19.00\%) GPs were highly significant more in comparison to MBBS GPs.

Banned drugs: like nimesulide in less than 12 year child was significantly $(\mathrm{p}=0.014)$ more in number were used by BAMS GPs.

No ORS in AGE patients is highly irrational. In patients of AGE, significant number of BAMS GPs did not prescribe ORS as compared to MBBS and BHMS GPs.

Overprescribing in which drug is given in larger doses or longer duration. BHMS GPs overprescribed more drugs $(\mathrm{p}=0.023)$.

Underprescribing in which drug is given for shorter duration was seen more in BAMS GPs $(p=0.002)$.

Table 5: Overall prescription.

\begin{tabular}{|lllll|}
\hline & $\begin{array}{l}\text { MBBS } \\
(\mathbf{n = 3 0 0})\end{array}$ & $\begin{array}{l}\text { BAMS } \\
(\mathbf{n = 3 0 0})\end{array}$ & $\begin{array}{l}\text { BHMS } \\
(\mathbf{n}=300)\end{array}$ & $\mathbf{p}$ value \\
\hline $\begin{array}{l}\text { Appropr } \\
\text { iate }\end{array}$ & $\begin{array}{l}213 \\
(71.00)\end{array}$ & $\begin{array}{l}119 \\
(39.66)\end{array}$ & $\begin{array}{l}104 \\
(34.66)\end{array}$ & $\mathrm{p}<0.0001 * * * *$ \\
\hline $\begin{array}{l}\text { Inappro } \\
\text { priate }\end{array}$ & $\begin{array}{l}87 \\
(29.00)\end{array}$ & $\begin{array}{l}181 \\
(60.34)\end{array}$ & $\begin{array}{l}196 \\
(65.34)\end{array}$ & $\mathrm{p}<0.0001 * * * *$ \\
\hline
\end{tabular}

Values in parentheses are in percentages $(\%)$

Table 5 shows overall inappropriate prescriptions were highly significantly more in BAMS and BHMS GPs in comparison to MBBS GPs ( $\mathrm{p}<0.0001)$.

\section{DISCUSSION}

The present study was a cross sectional, comparative study to evaluate prescriptions of General Practitioners (GPs) of private sector dispensaries in Pune city, individual prescriptions were analyzed to determine drugs used and assessed for its rationality.

Pune city was divided into 5 zones Central, North, South, East and West. We selected general practitioners listed with Indian Medical Association (IMA), Pune branch. More than $90 \%$ of practitioners listed with IMA, Pune branch have MBBS, BAMS or BHMS qualification. So MBBS, BAMS and BHMS practitioners were included in our study.
All the GPs were divided into 5 zones depending upon the location of their clinic. 2 GPs of each speciality per zone were selected by random sampling. 2 MBBS, 5 BAMS and 4BHMS GPs refused to participate in the study. These numbers of GPs were randomly selected again from the original list, zone wise. So, finally 10 Practitioners per speciality spread over Pune city were included in the study. 30 prescriptions were collected from each practitioner to get total 900 prescriptions. This was a prospective study carried out by directly observing the practices and prescriptions of GPs by sitting inside the OPDs of GPs.

Comparison of baseline characteristics of patients presenting to GPs revealed that Age and Sex distribution of patients presenting to MBBS, BAMS and BHMS GPS were comparable (Figure 1 and Figure 2). Distribution of patients based on diagnosis was also comparable across all practitioners (Figure 3). In Diagnosis wise distribution of patients, communicable diseases were most commonly encountered like URTI, AGE, Viral fever, UTI followed by LRTI (Figure 3 ).

Percentage of prescriptions with an antibiotic prescribed is to measure overall use of important but commonly overused and costly forms of drug therapy. ${ }^{12}$ As per WHO, percentage of prescriptions with an antibiotic prescribed ranges between $40-50 \%$ and is showing little upward trend. ${ }^{13}$

Antibiotic use reported from developing countries varies as per condition, facility and prescribers. Countries like Bangladesh $^{14}$ reported it to be $72.5 \%$, Pakistan $^{15}(62.3 \%)$. and $\mathrm{Nepal}^{16}(73.29 \%)$ showing wide variation in antibiotic prescribing. In India, percentage of encounters with an antibiotic was reported to be $75 \%$ by Kshirsagar et al. ${ }^{17} 34.4 \%$ by Hazra et al. ${ }^{18}$ and $68.1 \%$ by Kumari et al. $^{19}$

In the present study, percentage of prescriptions with antibiotic was $78.33 \%$ with MBBS, $77.33 \%$ with BAMS and $76.66 \%$ with BHMS GPs, the difference is not statistically significant $(p=0.053)$. Antibiotic use in our study was high in comparison to all above studies.

As seen in (Table 2); $\beta$ lactams, fluoroquinolones and Macrolides were important groups of AMAs used in treatment of infectious diseases. In $\beta$ lactam AMAs both penicillins and cephalosporins were used. Penicillins were more frequently used by MBBS GPs as against cephalosporins were more commonly used by BHMS GPs, the difference was statistically significant $(p=0.02)$. Macrolides were used equally by all GPs. Other AMAs included tetracyclines, antimalarials, antivirals and antifungals.

\section{Selection of AMAs based on diagnosis (Figure 5-7)}

URTI: MBBS GPs preferred Azithromycin, whereas BAMS and BHMS GPs preferred to give cephalosporins 
like cefexime and cefpodoxime. Both of these are $3^{\text {rd }}$ generation cephalosporins. Ideally penicillins, Macrolides or $1^{\text {st }}$ generation cephalosporins should be preferred for $1^{\text {st }}$ encounter RTI (URTI+LRTI) because $3^{\text {rd }}$ generations cephalosporins are mainly active against gram negative infections whereas RTIs are caused by gram positive organisms. ${ }^{10}$ So, use of $3^{\text {rd }}$ generation cephalosporins was considered inappropriate.

LRTI: MBBS GPs preferred cephalosporins, whereas BAMS GPs used penicillins. Ideally, amoxicillin or tetracyclines should be preferred for newly diagnosed LRTI. $^{10}$ So use of cephalosporins was considered inappropriate.

Viral Fever: MBBS preferred not to give AMAs, still some of them have prescribed AMAs. In case of BAMS and BHMS GPs, cephalosporins were used more commonly. Treating patients with the diagnosis of viral fever with AMAs is absolutely irrational practice. Only 13 patients of MBBS, 4 patients of BAMS and 6 patients of BHMS GPS were not given AMA in viral fever, so rest all were considered irrational.

UTI: Majority of MBBS, BAMS and BHMS GPs all preferred to give fluoroquinolones. In the treatment of UTI, some MBBS, BAMS and BHMS GPs have used cephalosporins, Quinolones and even Macrolides. Use of Macrolides in UTI was considered inappropriate.

AGE: MBBS, BAMS and BHMS GPs preferred to give combination of fluoroquinolones with imidazoles. In general, most cases of acute gastroenteritis are selflimited and do not require therapy other than supportive measures. Treatment usually should consist of replacement of fluids and electrolytes. Fluoroquinolones like ciprofloxacin and norfloxacin can be used. Fluoroquinolones with imidazoles (Tinidazole / ornidazole) was considered inappropriate. ${ }^{20}$

For rationality of use of AMA we considered the ABC criteria by Badar et al. ${ }^{9}$ i.e. A (Rational), B (Irrational) and $\mathrm{C}$ (Questionable). According to this criteria, in our study (Table 3) MBBS GPs prescribed AMAs significantly more rationally $(\mathrm{p}=0.008)$ in comparison to BAMS and BHMS GPs.

\section{$\operatorname{MBBS}(79.23 \%)>\operatorname{BAMS}(53.44 \%)>\operatorname{BHMS}(51.30 \%)$}

Number of irrational AMA prescriptions were highly significantly more $(\mathrm{p}=0.0005)$ in BHMS and BAMS GPs in comparison to MBBS.

\section{BHMS $(41.30 \%)>$ BAMS $(33.62 \%)>\operatorname{MBBS}(15.25 \%)$}

Over the period, average number of drugs per prescription has remained 2 to 3 as reported by INRUD. ${ }^{13}$ In Indian studies, average number of drugs per prescription was reported to be- 3.7 by Patel et al. ${ }^{21}, 2.8$ by Kshirsagar et al. ${ }^{17}$ and 3.6 by Lalan et al. ${ }^{22}$ In the present study, for
MBBS practitioners it was 3.95, for BAMS practitioners it was 4.98 whereas for BHMS practitioners it was 4.64. The difference was not statistically significant. The average number of drugs per encounter is an important index of the scope for educational intervention in prescribing practices. Our figure of $>3$ drugs per encounter in all GPs is much higher than the recommended limit of 2.0. ${ }^{23}$ In BAMS and BHMS GPs, average number of drugs per prescription is $>4$, this may be due to treatment based on symptoms rather than the diagnosis. Such irrational polypharmacy leads to the risk of drug interactions, dispensing errors, emergence of resistance, increased cost of therapy and increased adverse reactions. $^{24}$

The development of fixed-dose combinations (FDCs) is becoming increasingly important from a public health perspective. $^{25}$ MBBS GPs prescribed $24.92 \%$ of FDCs; BAMS GPs prescribed $19.10 \%$ of FDCs whereas BHMS GPs prescribed $18.50 \%$ of FDCs, the difference was statistically significant $(\mathrm{p}=0.027)$. Use of FDCs varies a lot amongst different studies e.g. Vijaykumar et al. $(16.8 \%)^{26}$ and Kastury et al. $(75 \%){ }^{27}$ We considered FDCs rational or irrational as per the FDC listed in Essential Medicines Model List, India 2011. ${ }^{28}$

Use of steroids in treatment of minor infections is totally irrational practice. Dexamethasone was the commonest steroid which was dispensed by GPs. BAMS GPs prescribed steroids to $22.33 \%$ patients, BHMS GPs prescribed to $19.00 \%$ patients whereas MBBS prescribed steroids to $5.66 \%$ of patients, the difference was statistically significant $(\mathrm{p}<0.0001)$. Drugs banned by DCGI (Drugs Controller General of India) and by WHO were considered. We came across doctors prescribing Nimesulide in children <12years and furazolidone for AGE.BAMS GPs prescribed banned drugs to $6.33 \%$ patients as compared to BHMS (1.33\%) and MBBS $(1.00 \%)$, the difference was statistically significant $(p=0.014)$. Use of Oral Rehydration Solution is considered to be first line of treatment for acute diarrhoea according to existing guideline. ${ }^{12}$ It is highly irrational not to prescribe it. In our study, BAMS GPs did not prescribe ORS in $36.95 \%$ of AGE patients which is very high compared to BHMS (25.58\%) and MBBS (3.92\%) GPs, the difference was statistically significant $(\mathrm{p}=0.016)$.

Overprescribing means drugs prescribed in overdose or for longer period which can lead to the development of toxicity. For example one of the GPs dispensed Paracetamol 500mg three times a day for fever in an addition to Tab. fepanil (Paracetamol) 650mg bd, which is overprescribing. BHMS GPs overprescribed in $20.66 \%$ of patients as compared to BAMS (16.66\%) and MBBS $(9.00 \%)$, the difference was statistically significant $(\mathrm{p}=0.023)$. Underprescribing is also a serious problem. Underprescribing is considered to have happened when a drug is given in fewer doses and/or for shorter duration. Reduced efficacy leading to requirement of aggressive or expensive treatment at later date may occur. ${ }^{11}$ For 
example one of the GP prescribed Levofloxacin 500mg od only for 2 days. In our study, BAMS GPs underprescribed in $23.00 \%$ patients as compared to MBBS (11.00\%) and BHMS (8.00\%), the difference was statistically significant $(\mathrm{p}=0.002)$.

For overall prescription, individual drugs prescribed were evaluated as described above. Prescriptions with inappropriate use of drugs were rated as inappropriate prescription. Appropriate- $71 \%$ of prescriptions of MBBS GPs were appropriate as compared to BAMS with $39.66 \%$ and BHMS with $34.66 \%$, the difference was statistical significant $(\mathrm{p}<0.0001)$. Inappropriate- $65.34 \%$ prescriptions of BHMS GPs were inappropriate as compared to BAMS with $60.34 \%$ and MBBS with $29 \%$, the difference was statistical significant $(p<0.0001)$.

Appropriateness of prescriptions of MBBS GPs also evaluated by Dutta et al. $^{24} 63.51 \%$ prescriptions were found inappropriate. Inappropriate prescriptions reported by Bhatnagar et al. ${ }^{29}$ were $60 \%$ and $68 \%$ by WHO in Asian countries. ${ }^{13}$ In comparison to these results, only $29 \%$ prescriptions of MBBS GPs were inappropriate in our study. But $>60 \%$ of prescriptions of BAMS and BHMS GPs were inappropriate.

\section{CONCLUSION}

To conclude, our study has highlighted the current status of treatment practices of general practitioners in Pune city. There are deficiencies in prescription practices among BAMS and BHMS general practitioners as well as MBBS practitioners. The results indicate a considerable scope for improvement in prescribing pattern of general practitioners in there out-patient department. There is some evidence that interventions like short problem based training course in pharmacotherapy ${ }^{30}$ and rational use focused workshops ${ }^{31}$ can improve prescribing pattern.

This study has a limitation that the total number of general practitioners was only thirty and more studies are needed to be carried out in order to confirm these findings.

\section{ACKNOWLEDGMENTS}

The author's thank the Indian Medical Association, Pune Branch for providing all the necessary support and cooperation. The help rendered by Dr. Deepak. Langade, Clinsearch, Mumbai for statistical support for the project is thankfully acknowledged.

Funding: No funding sources

Conflict of interest: None declared

Ethical approval: The study was approved by the Institutional Ethics Committee (BVDU/MC/1555/20102011)

\section{REFERENCES}

1. World Health Organization. The Rational Use of Drugs. Report of the Conference of Experts. Geneva: World Health Organization; 1985.

2. Chaudhury RR. Rational Use of Drugs. The Journal of Family Welfare. 2004;50:92-4.

3. Das BP, Sethi A, Rauniar GP, Sharma SK. Antimicrobial utilization pattern in outpatient services of ENT department of tertiary care hospital of Eastern Nepal. Kathmandu University Medical Journal. 2005;3(12).370-5.

4. World Health Organization. Guide to Good Prescribing. Geneva: World Health Organization; 1994.

5. Ramsay L E. Bridging the gap between clinical pharmacology and rational drug prescribing. $\mathrm{Br} \mathrm{J}$ Clin Pharmacol. 1993;35:575-6.

6. Pradhan SC, Shewade DG, Shashindren CH, Bapna .IS. Drug utilization studies. National Med Jour India 1988; 1:185-89.

7. Ganguly E, Deshmukh PR, Garg BS. Quality assessment of private practitioners in rural Wardha, Maharashtra. Indian J Community Med. 2008;33:357.

8. General Practitioner: Wikipedia. Available at: URL:http://en.wikipedia.org/wiki/General_Practition er. Last accessed 17.10.2013.

9. Badar VA, Sanjaykumar BN. Study of Prescribing Pattern of Antimicrobial Agents in Medicine Intensive Care Unit of a Teaching Hospital in Central India. JAPI. 2012April;60:20-3.

10. Tiernay LM, Papadakis MA, Mcphee SJ. Current Medical Diagnosis \& Treatment. $51^{\text {st }}$ ed. New York: McGrawHill; 2012.

11. Bhaskar I and Bhushan A.Auditing of Prescribing Pattern of Doctors In Tertiary Care Centre In Bangalore. Pharmacologyonline. 2011:1:405-8.

12. World Health Organization. How to investigate drug use in health facilities: Selected drug use indicators EDM Research series No. 7. Department of Essential drugs \& medicines policy. Geneva: WHO1993 (reprint2006): 3-16.

13. Holloway Kathy, Promoting Rational Use of Medicines: INRUD NEWS. 2006Dec;16(1):3-5.

14. Zaida R, Nazneen R, Mahmuda B. Evaluation of prescribing pattern of the private practitioners by the undergraduate medical students. Bangladesh J Pharmacol. 2009;4:73-5.

15. Siddiqi, S. et al. Prescription practices of public and private health care providers in Attock District of Pakistan. Int. J. Health Plann. Mgmt. 2002:17:23-40.

16. Das BP, Sethi A, Rauniar GP, Sharma SK. Antimicrobial utilization pattern in outpatient services of ENT department of tertiary care hospital of Eastern Nepal. Kathmandu University Medical Journal. 2005;3(12).370-5.

17. Kshirsagar MJ, Langade D, Patil S and Patki PS. Prescribing patterns among medical practitioners in 
Pune, India. Bulletin of the World Health Organization. 1998;76(3):271-5.

18. Hazra A, Tripathi SK, Alam MS. Prescribing and' dispensing Activities at the Health Facilities of a Non-Governmental Organization. The National Medical Journal of India. 2000;13(4).177-82.

19. Kumari IS, Chandy SJ, Jeyaseelan L, Kumar R, Suresh S. Antimicrobial prescription patterns for common acute infections in some rural \& urban health facilities of India. Indian $\mathrm{J}$ Med Res. 2008Aug;128(2):165-71.

20. Kakkilaya BS. Rational Use of Antibiotics. Available http://www.rationalmedicine.org/antibiotics.htm. Last accessed 23/10/13.

21. Patel S. et al. Evaluation and Comparison of Prescribing Pattern of General Practitioners from Public and Private Sectors. National Journal of Physiology, Pharmacy \& Pharmacology. 2012:2(1):33-8.

22. Lalan B, Hiray R, Ghongane B. Drug Prescription Pattern of Outpatients in a Tertiary Care teaching Hospital In Maharashtra. Int J Pharm Bio Sci. 2012July;3(3):225 - 9.

23. Sharif SI, M Al-Shaqra, Hajjar H, Shamout A, and Wess L. Patterns of Drug Prescribing In a Hospital In Dubai, United Arab Emirates. Libyan J Med. 2008;3(1):10-12.

24. Dutta A, Chakraborty S. Practice of rational drug uses in a rural area of $24 \mathrm{pgs}(\mathrm{s})$ in West Bengal. J Adv Pharm Tech Res. 2010;1:358-64.
25. Fixed Dose Combination. Available at http://apps.who.int/prequal/info_applicants/Guidelin es/info_for_applicants_guidelines_fdcs.htm. Last accessed 23/10/13.

26. Vijayakumar TM, Sathyavati D, Subhashini T, Gandhi S. and Dhanaraju MD. Assessment of Prescribing Trends and Rationality of Drug Prescribing. International Journal of Pharmacology. 2011:7:140-3.

27. Kastury N, Singh S, Ansari K. An Audit of Prescription for Rational Use of Fixed Dose Drug Combinations. Indian Journal of Pharmacology. 1999;31:367-9.

28. Fixed dose combinations and Banned drugs list Available at http://www.cdsco.nic.in/. Last accessed 23/10/13.

29. Bhatnagar T, Mishra C and Mishra R. Drug Prescription Practices: A Household study In Rural Varanasi. Indian J Prev Soc Med. 2003:34(2);33-9.

30. Akici A, Kalaça S, Ugurlu MU, Karaalp A, Cali S, Oktay S. Impact of a short postgraduate course in rational pharmacotherapy for general practitioners. Br J Clin Pharmacol. 2004Mar;57(3):310-21.

31. Thomas M, Cherian AM, Mathai D. Measuring the impact of focused workshops on rational drug use. Trop Doct. 1997 Oct;27(4):206-10.

doi:10.5455/2319-2003.ijbcp20140220

Cite this article as: Sarda KD, Pandit VA. Assessment of antimicrobial prescribing and rationality of drug usage in general practitioners in Pune city, India. Int $\mathbf{J}$ Basic Clin Pharmacol 2014;3:155-63. 